\title{
THREE-DIMENSIONAL (3D) MODELLING OF THE PEDESTRIAN BRIDGE OVER THE RIVER NERIS
}

\author{
R. Cechavicius ${ }^{1}$, J. S. Visockiene ${ }^{1}$, E. Tumeliene ${ }^{1}$ \\ ${ }^{1}$ Vilnius Gediminas Technical University, Department of Geodesy and Cadastre - \\ rokas.cechavicius@stud.vilniustech.lt, (juratesuziedelyte-visockiene, egle.tumeliene)@ vilniustech.lt
}

Commission V, WG V/7

KEY WORDS: 3D model, Cloud-to-Cloud error, Ground Control Point, Trimble X7, Scanning results.

\begin{abstract}
:
With the rapid development of new technologies, there is a growing necessity to optimize and to digitize as much as it is possible in all areas of work, including the designs of new facilities. Pre-formation of location's 3D model (by scanning) allows us to evaluate how the newly constructed object will integrate into the territory. The object of research is the pedestrian bridge over the river of Neris in Vilnius city (Lithuania). The aim of the research is to create a 3D model of the embankments of river Neris which will be required for the integration of the future bridge model. Equipment used for scanning of the embankments: scanner Trimble X7, tablet T10 with new software Trimble Perspective and device Survey Mobile Point. Measurement results were processed using the program Trimble Real Works. Scanning points, geodetic data and other available data were integrated into the program. Scanning results (generated 3D models) and the project of river embankments were combined into a general model. The model was coordinated and data "garbage" was removed. Cloud-to-Cloud errors, point's coincident percent and results confidence have been identified during the modelling - joint between the scanning stations. The Cloud-to-Cloud errors of the connection between two embankments ranged from $1 \mathrm{~mm}$ to $28 \mathrm{~mm}$. Points coincident percent varies from 25 to $62 \%$. The largest errors and the smallest coincident percent occurs by combining two sides of the embankments together into one model. The smallest errors and the largest coincident percent were between the one-side scanning stations point clouds. In the general project of embankments and the bridge project, some discrepancies were identified due to possible project coordination or modelling errors.
\end{abstract}

\section{INTRODUCTION}

Paradoxically, but the history of 3D modeling began way before the first PC appeared. It all started with mathematical ideas which talk about 3D visualization (History of 3D modeling...,2021). The basic idea was proposed by „geometry discoverer" Euclid'o. Later in the 17th century Rene Descartes named it „analytical geometry“. This theory is also called coordinate geometry, because it was used to determine accurate distances and locations. English mathematician James Joseph Sylvester in the middle of the 18th century invented matrix mathematics, which now is used for every computer generated image and in which reflections or distortions of light are visible. In the second half of 20 century computers were developed and adapted for mathematical use, for military and scientific purposes. The speed of automation and image transformation encouraged new activities such as animation creation, television and advertising (Horain, 1998). 3D models became useful in many other fields such as component design, engineering or medicine. This contributed to global growth of industry and healthcare (Fassi, 2007; Özsoy, 2019). Lithuania is no exception in this process too. Building information modeling (BIM) technology is widely used and some digital construction methods have been used in the country for more than 10 years (Dvilinskas, 2015). Office building in the city Klaipeda is the first 3D modeling experiment in Lithuania (2002). Development of the 3D model of the building of Vilnius city Municipality (2003-2006) was combined with the analytical calculations of the building. Executive project documentation together with other information concerning building management was stored in a database associated with the model (a prototype of a six dimensional (6D) model).
BIM technology is very popular now and is used in the design of many existing or future city buildings (Smart city). 3D models depict a physical body using 3D point cloud space, connecting various geometric objects such as triangles, lines, curved surfaces and other. 3D models (points and other information) are generated using the algorithm (procedural modelling), photogrammetry or scanning method (Loredo Conde et. al., 2020). The 3D surface can be additionally defined depicting the texture (Yih Lai et al., 2018).

The new modelling method was used to create a 3D model of the embankments of the river Neris which will be required for the integration of the future bridge model. The aim of the project is to improve the infrastructure of pedestrians and bicycles from Žverynas living area to the center of the city Vilnius. (Figure 1.) (New infrastructure..., 2021).

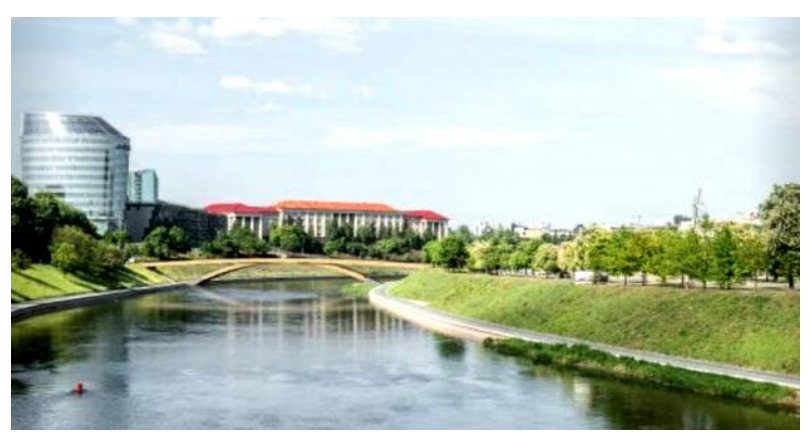

Figure 1. New infastructure project in Vilnius city. 


\section{MATERIALS AND METHOD}

\subsection{Location and description of the study area}

The designed bridge is assigned to special buildings. The completion of construction is planned for 2023. Although the bridge is only at the planning stage and the project proposals are accepted, a 3D visual view of the project has already been created. Location of the bridge is the Elderships of Žvèrynas and Naujamiestis, between streets Upès and A. Goštautas (Figure 2.). The projected area is on a free, unformed state land and the project plots (No. 1 - area 3.32 ha and No. 2 - area 1.49 ha) are not registered. There are no existing registered buildings in the projected territory. The surrounding areas are of a high level of urbanisation, with residential, administrative and other buildings nearby.

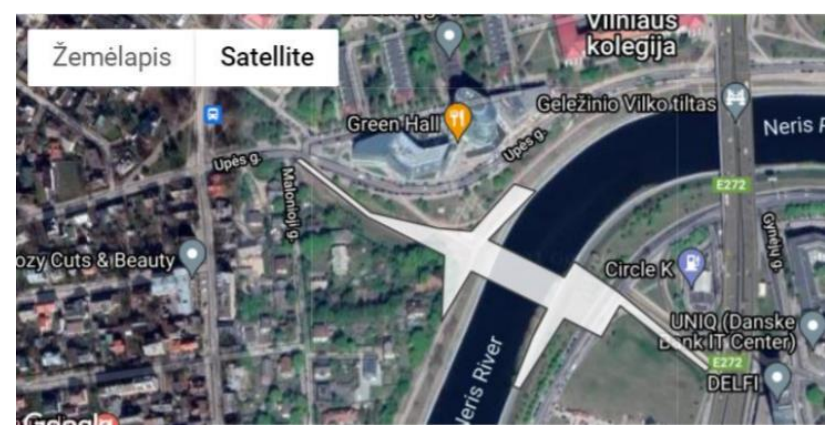

Figure 2. Dislocation of new bridge over the river Neris (Vilnius, Lithuania).

The scanning method was used to create a 3D model of embankments of the river Neris near the planned bridge. Used devices and software are described in section 2.2.

\subsection{Devices for modelling}

Modern 3D scanner is a combination of various measurement technologies. It consist from components of equipment of traditional measurement and photography: camera to capture the real colours of the objects; tilt inclination sensors (the device does not require levelling); measurement method based on level and tacheometer functionality; GPS receiver - to determine the exact position; compass - to determine preliminary direction and other details. Currently it is the most reliable equipment for data collection. High-speed 3D laser scanning system, Trimble X7 Scanner, T10 tablet with new Trimble Perspective software, Spectra SP60 GNSS receiver, phone with software Spectra Survey Mobile was used for the research (Figure 3).
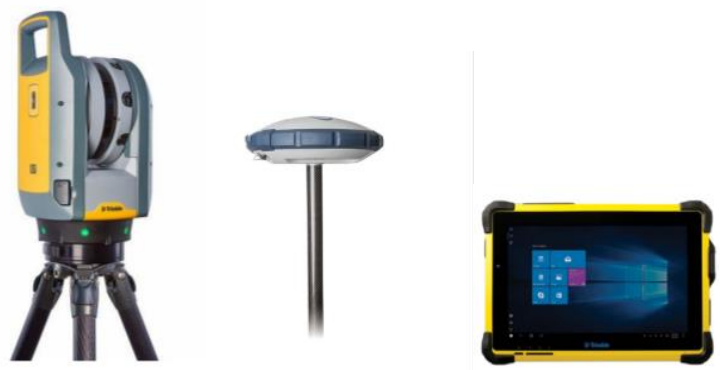

Figute 3. High-speed 3D laser scanning system: a) Trimble X7; b) SP60 GNSS receiver; c) Trimble T10 tablet.
The characteristics of the laser scanner Trimble X7 are presented in Table 1.

\begin{tabular}{|l|l|}
\hline Characteristics & Values \\
\hline $\begin{array}{l}\text { Maximum work } \\
\text { distance }\end{array}$ & $80 \mathrm{~m}$ \\
\hline $\begin{array}{l}\text { Geometrical } \\
\text { accuracy of scanning } \\
\text { point }\end{array}$ & $3.5 \mathrm{~mm}$ over $20 \mathrm{~m}$ \\
\hline Self-levelling & $\begin{array}{l}\text { Automatic survey grade level } \\
\text { compensation in 3 sec }\end{array}$ \\
\hline Speed of scanning & From 1 min 34 sec \\
\hline Weight with battery & $5.8 \mathrm{~kg}$ \\
\hline Laser Pointer & $\begin{array}{l}\text { Provides visual confirmation of } \\
\text { individual points to be measured by } \\
\text { Trimble Perspective }\end{array}$ \\
\hline $\begin{array}{l}\text { Automatic } \\
\text { Calibration }\end{array}$ & $\begin{array}{l}\text { Complete confidence in every scan } \\
\text { with the industry's first smart } \\
\text { calibration system. No targets or user } \\
\text { interaction required. On-Demand } \\
\text { calibration reports }\end{array}$ \\
\hline
\end{tabular}

Table 1. Characteristics of Trimble X7 laser scanner

The Trimble X7 solution is fully integrated with the new Trimble Perspective software specifically designed for in-field control and complete registration. The combination enables scans and images to be captured, fully registered together, refined, controlled and exported to a variety of established data formats for Trimble and non-Trimble software suites (Trimble X7 Scanner, 2021). The Trimble T10 is a powerful, rugged device created for survey fieldwork and GIS data collection (Trimble T10, 2021). The SP60 GNSS receiver has been designed to meet the needs of surveyors or location professionals. Extremely scalable and versatile, the SP60 can be used for virtually any task from simple GIS workflows to the most demanding surveying jobs (SP60, 2021). The measurement tool Spectra Survey Mobile was used for equipment with the operating system Android. This geodetic program, unlike complex and detailed computer programs, has only basic measurement functions. This makes working with this program easier and faster. This program is suitable for surveyors which want to perform works quickly and easily (Spectra Survey Mobile, 2021). Trimble RealWorks software for point cloud processing and analyses was used for this work. River embankments point cloud data and other geodetic data were integrated into the program. The result is - combined point cloud data and generated 3D models (Trimble RealWorks, 2021).

\subsection{Modelling process in object}

Ground control points (GCP) are selected and coordinated to create a 3D model in the area. Measurements were performed with an SP60 GNSS receiver attached to a 2 meter long holder. A new work folder was created in the Survey Mobile program. The GNSS receiver via wireless Bluetooth is connected to the program. To ensure the accuracy of the measurements the device is connected to the RTK network: LitPos (Lithuania) coordinate system. Program's function „Point survey“ was used to measure the points. Coordinated 16 GCP points presented in Figure 4. The horizontal accuracy of the measured points did not exceed $11 \mathrm{~mm}$ and the vertical accuracy (height) $-18 \mathrm{~mm}$. To obtain sufficient data for interconnection it is important to choose the right stations for the scanning process. Six stations were installed on each river embankment ( 3 at the top of the embankment and 3 at the bottom) for this purpose (Figure 5). 

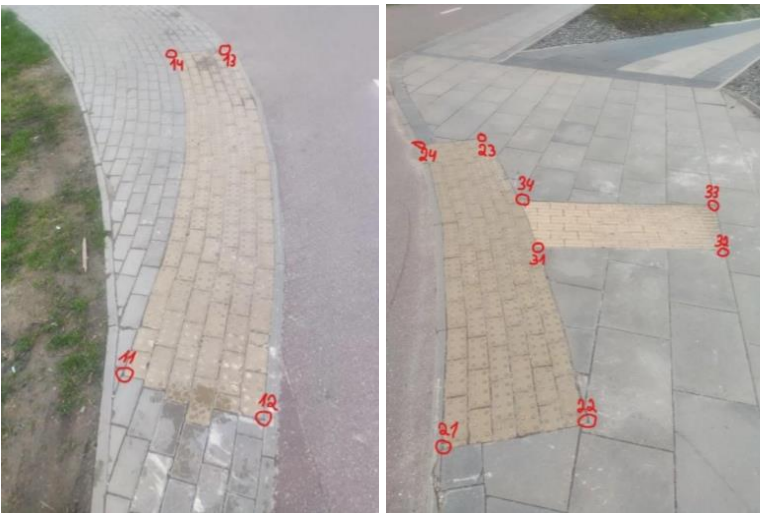

Figure 4. Coordinated 16 GCP points in the area.

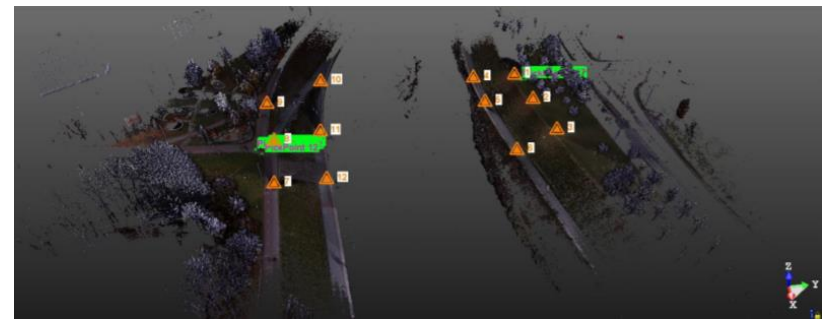

Figure 5. Scanning stations on both embankments (1-12).

The scanning was done by a scanner Trimble X7 and T10 tablet with Trimble Perspective program. Photography of the territory done additionally. All scanning data of stations are exported to the wanted parameters (units of measure, dot cloud shading etc.). Data from Trimble Perspective is exported in just a few minutes and the process of data importing for their processing into Trimble RealWorks program takes about an hour. Destruction of unnecessary objects such as grass, birds, things and passing people require a lot of time. However, this process reduces the cloud size of the model and it becomes easier to see the real object. The overlap between the embankments is small, so coordinating both embankments the average error was 45 $\mathrm{mm}$, coordinating each one individually $-1,3 \mathrm{~mm}$. The Trimble RealWorks Modelling module was used to create partial or full models and was particularly suited for applications where modelled geometries enhance or complete the impact and scope of intermediate and final deliverables. Into the generated joint 3D model of both embankments a 3D model project of the bridge was uploaded for the geometric analysis (Figure 6).

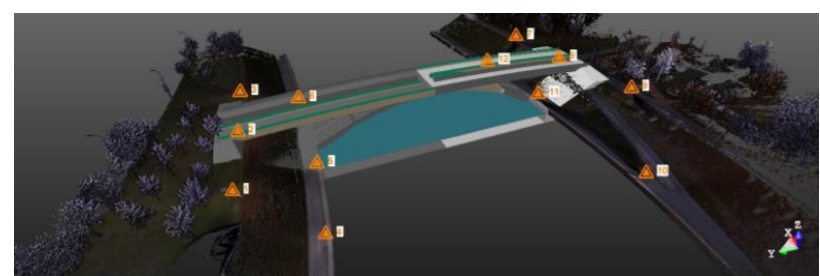

Figure 6. Model of the bridge uploaded in to the project of embankments.

Discrepancies between 3D embankments model and the project model was observed. Discrepancies occur due to different GCP coordination data and merge errors of embankments which are away from each other. Merge accuracy of scanning stations is presented in chapter 3 .

\section{QUALITY RESULT OF 3D MODEL OF THE PEDESTRIAN BRIDGE OVER THE RIVER NERIS}

The point clouds of scanning stations (1-12) were connected together to generate the $3 \mathrm{~d}$ model of the embankments Cloud to - Cloud merge error mm, Coincident point and Confidence level percentage expression is presented in Table 2. 1-3 scanning stations were in the top of the right pedestrian side, 4-6 - in the bottom. Also, 7-9 - in the top of the left pedestrian side, 10-12 in the bottom.

\begin{tabular}{|c|c|c|c|c|}
\hline $\begin{array}{l}\text { Station } \\
\text { No. }\end{array}$ & $\begin{array}{c}\text { Connection } \\
\text { station } \\
\text { No. }\end{array}$ & \begin{tabular}{|c|} 
Cloud-to- \\
Cloud \\
error, $\mathrm{mm}$
\end{tabular} & $\begin{array}{c}\text { Coincident } \\
\text { point, } \\
\%\end{array}$ & $\begin{array}{c}\text { Confidence, } \\
\%\end{array}$ \\
\hline \multirow[t]{3}{*}{1} & 2 & 5.07 & 64 & 100 \\
\hline & 4 & 4.79 & 33 & 96 \\
\hline & 5 & 4.88 & 44 & 99 \\
\hline \multirow[t]{4}{*}{2} & 1 & 5.07 & 64 & 100 \\
\hline & 3 & 6.75 & 65 & 100 \\
\hline & 5 & 1.11 & 44 & 99 \\
\hline & 6 & 1.22 & 37 & 98 \\
\hline \multirow[t]{2}{*}{3} & 2 & 6.75 & 65 & 100 \\
\hline & 6 & 6.02 & 54 & 100 \\
\hline \multirow[t]{3}{*}{4} & 1 & 4.79 & 33 & 96 \\
\hline & 5 & 1.02 & 58 & 100 \\
\hline & 10 & 24.83 & 39 & 98 \\
\hline \multirow[t]{4}{*}{5} & 1 & 4.88 & 44 & 99 \\
\hline & 2 & 1.11 & 44 & 99 \\
\hline & 4 & 1.02 & 58 & 100 \\
\hline & 11 & 27.49 & 39 & 98 \\
\hline \multirow[t]{3}{*}{6} & 2 & 1.22 & 37 & 98 \\
\hline & 3 & 6.02 & 54 & 100 \\
\hline & 12 & 28.38 & 31 & 95 \\
\hline \multirow[t]{2}{*}{7} & 8 & 1.96 & 62 & 100 \\
\hline & 12 & 1.51 & 48 & 99 \\
\hline \multirow[t]{4}{*}{8} & 7 & 1.96 & 62 & 100 \\
\hline & 9 & 2.58 & 53 & 100 \\
\hline & 11 & 1.61 & 38 & 98 \\
\hline & 12 & 1.92 & 38 & 98 \\
\hline \multirow[t]{2}{*}{9} & 8 & 2.58 & 53 & 100 \\
\hline & 10 & 3.22 & 35 & 97 \\
\hline \multirow[t]{3}{*}{10} & 4 & 24.83 & 39 & 98 \\
\hline & 9 & 3.22 & 35 & 97 \\
\hline & 11 & 8.55 & 25 & 90 \\
\hline \multirow[t]{4}{*}{11} & 5 & 27.49 & 39 & 98 \\
\hline & 8 & 1.61 & 38 & 98 \\
\hline & 10 & 8.55 & 25 & 90 \\
\hline & 12 & 1.38 & 61 & 100 \\
\hline \multirow[t]{4}{*}{12} & 6 & 28.38 & 31 & 65 \\
\hline & 7 & 1.51 & 48 & 99 \\
\hline & 8 & 1.92 & 38 & 98 \\
\hline & 11 & 1.38 & 61 & 100 \\
\hline
\end{tabular}

Table 2. Registration Report using Scans data

Interconnected point clouds of stations 1-6 on the right side of embankments do not exceed $7 \mathrm{~mm}$ error and number of total points varies from $30-65 \%$. The reliability of results is high from 95 to $100 \%$. When point clouds of stations $10-12$ on the left side of embankments were included in to process the connection errors increase from 24 to $27 \mathrm{~mm}$ and the number of total points does not exceed $39 \%$. The reliability of results remains high from 65 to $98 \%$. The results allow us to conclude that to ensure accuracy of the 3D model it is necessary to be accurate and stations have to be close to each other. However, if the research object is a river surface and it is no possibilities to form a scanning station, then it is recommended to form two 
separate 3D models of the right and left embankments. Subsequently it is not difficult to place all results into a common set of data for joint aggregation and analysis.

\section{CONCLUSIONS}

Equipment used for scanning of the embankments and 3D model creation: scanner Trimble $X 7$, tablet T10 with new software Trimble Perspective and device Survey Mobile Point. Preparation of devices for work is quick and the process of measurement is uncomplicated. Technical use of Scanner Trimble $X 7$ is easy to assimilate. After scanning the river Neris embankments large surface point clouds $(3.4 \mathrm{gb})$ were created. Using software Trimble RealWorks data was merged into a common 3D model of river embankments. Errors of scanning stations point cloud merging varies from 1 to $28 \mathrm{~mm}$. The size of errors depends on the distance between the scanning stations. Combining the 3D data of river embankments and 3D model of bridge the discrepancies were observed. Reasons of discrepancies occur: different GCP points used for both models, location of scanned stations in embankments and accuracy of their combining.

Suggestions. In order to reduce the errors of combining, it is recommended not to register embankments together and to coordinate them separately. This will reduce coordination errors and a better compliance between embankments model and the bridge project would be achieved. Pre-selection and indication of scanning location is important too. A large number of prepared markers would ensure better integration of 3D models. In this case a big part of the stations would be connected automatically and the coordination would become more accurate.

\section{ACKNOWLEDGEMENTS}

The authors would like to thank the private company UAB "GeoNovus" which allowed us to use their equipment for this research.

\section{REFERENCES}

Dvilinskas, J., 2015: The first Lithuanian BIM seedlings (in Lithuanian). Digital building. http://www.darnistatyba.lt/pirmieji-lietuviski-bim-daigai/

Fassi, F., 2007: 3D Modeling Of Complex Architecture Integrating Different Techniques-A Critical Overview. ISPRS, 3D-ARCH $2007 \quad$ Proceedings. https://www.academia.edu/2214518/3D_Modeling_Of_Comple X_Architecture_Integrating_Different_Techniques_A_Critical_ Overview (29 November 2021).

History of 3D modeling: from Euclid to 3D printing. Open Source https://ufo3d.com/history-of-3d-modeling/ (29 November 2021).

Horain, P., 1998: 3D modeling for multimedia applications. Open Source https://www.researchgate.net/publication/228569079_3D_mode ling_for_multimedia_applications (29 November 2021).

Yih Lai, J., Chien Wu, T., Phothong, W., Wang, D., 2018: A High-Resolution Texture Mapping Technique for 3D Textured Model. Apply Science, 8(11):2228, DOI:10.3390/app8112228.
Loredo Conde, A. J., Garcia Sanz-Calcedo, J., Reyes Rodríguez, A. M., 2020: Use of BIM with photogrammetry support in small construction projects. Case study for commercial franchises. Journal of Civil Engineering and Management 26(6):513-523, DOI:10.3846/jcem.2020.12611.

New infastructure project in Vilnius city, 2021. Open Source https://citify.eu/wp-content/uploads/2019/04/Citify-Pesciujutiltas-per-Neri-ties-Green-Hall-06.jpg (29 November 2021)

Özsoy, Ö., 2019: Evaluation of 3D Modeling Programs For Industrial Design Use. Journal of Polytechnic, DOI:10.2339/politeknik.481241.

SP60. https://spectrageospatial.com/sp60-gnss-receiver/ November 2021)

Trimble RealWorks. Open Source https://geospatial.trimble.com/products-and-solutions/trimblerealworks (29 November 2021)

Trimble $\mathrm{T} 10$

https://geospatial.trimble.com/sites/geospatial.trimble.com/files/ 2019-06/Datasheet\%20-\%20Trimble\%20T10\%20Tablet\%20\%20English\%20A4\%20-\%20Screen.pdf (29 November 2021).

Trimble X7 Scanner. Open Source https://geospatial.trimble.com/x7-scanner (29 November 2021). 